\title{
ESTUDO SOBRE O COMPORTAMENTO DE HELICONIUS ERATO PHYLLIS EM RECINTO FECHADO
}

\section{Mariana Tiemi Miura ${ }^{1}$ \\ Luciana Cássia Guedes²}

Resumo: Constituindo a segunda ordem de insetos mais abundante, os lepidópteros possuem uma infinidade de características comportamentais, sendo de suma importância o estudo destas para auxiliar na conservação das espécies, uma vez que, grande parte da biodiversidade é perdida devido à acelerada degradação do meio ambiente. O trabalho foi realizado através de observações de todas as etapas do ciclo de vida de Heliconius erato phyllis em um borboletário, podendo ser constatada a fácil adaptabilidade ao habitat e alta longevidade dos indivíduos estritamente relacionados à sua alimentação, obtendo comportamentos semelhantes aos de espécimes de vida livre.

Palavras-chave: Etologia; Borboletário; Lepidoptera; Heliconiinae.

\footnotetext{
${ }^{1}$ Centro de Estudos da Natureza/Universidade do Vale do Paraíba, Brasil. E-mail: mariana_miura@hotmail.com. 2 Instituto da Ciência e da Saúde/Universidade Paulista, Brasil. E-mail: lucianacguedes@hotmail.com.
} 